\title{
Frost growth and densification in laminar flow over flat surfaces
}

\author{
Max Kandula \\ ASRC Aerospace, John F. Kennedy Space Center, FL 32899, USA \\ E-mail address: max.kandula-1@nasa.gov
}

\begin{abstract}
One-dimensional frost growth and densification in laminar flow over flat surfaces has been theoretically investigated. Improved representations of frost density and effective thermal conductivity applicable to a wide range of frost circumstances have been incorporated. The validity of the proposed model considering heat and mass diffusion in the frost layer is tested by a comparison of the predictions with data from various investigators for frost parameters including frost thickness, frost surface temperature, frost density and heat flux. The test conditions cover a range of wall temperature, air humidity ratio, air velocity, and air temperature, and the effect of these variables on the frost parameters has been exemplified. Satisfactory agreement is achieved between the model predictions and the various test data considered. The prevailing uncertainties concerning the role air velocity and air temperature on frost development have been elucidated. It is concluded that that for flat surfaces increases in air velocity have no appreciable effect on frost thickness but contribute to significant frost densification, while increase in air temperatures results in a slight increase the frost thickness and appreciable frost densification.
\end{abstract}




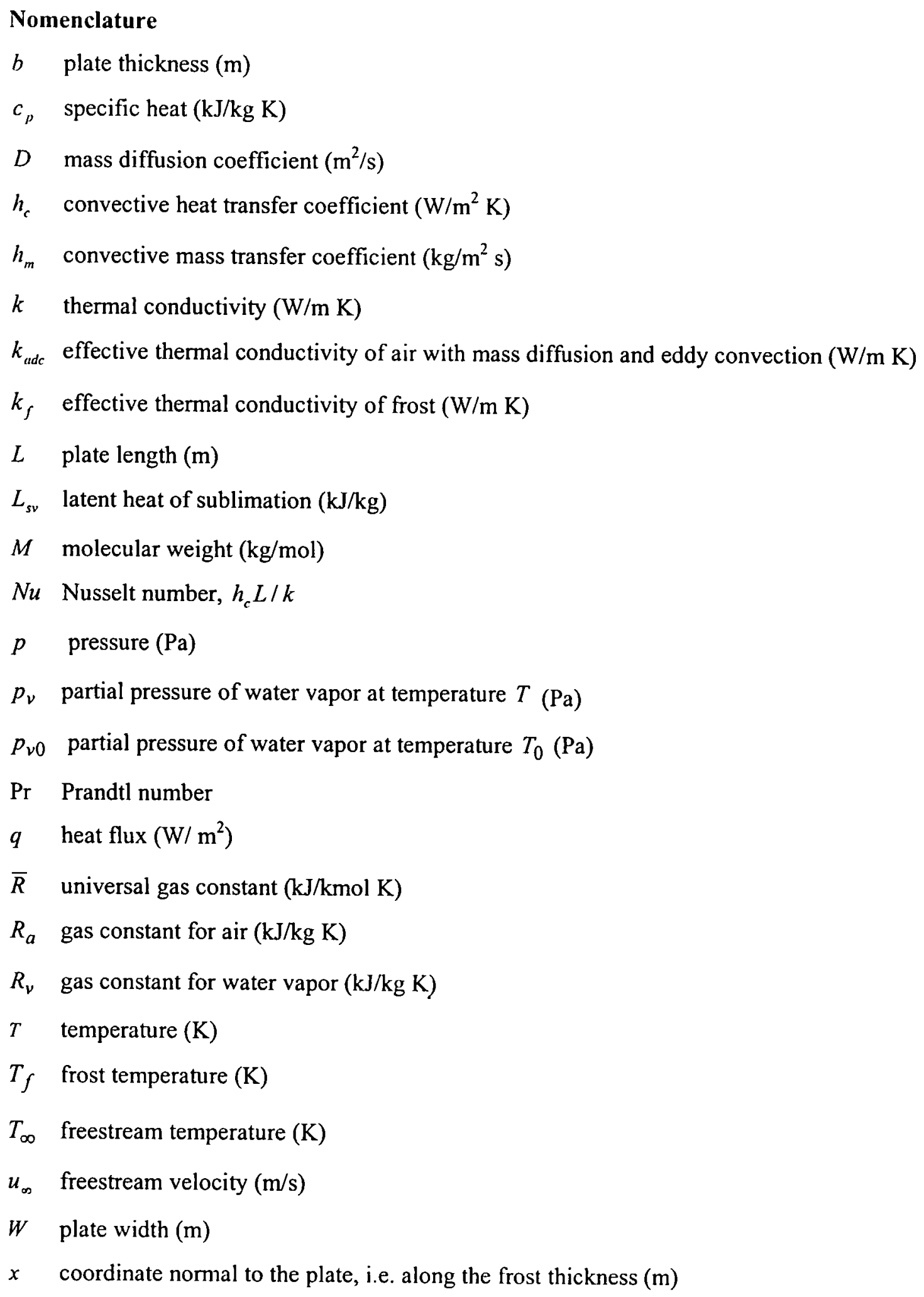




\section{Greek Symbols}

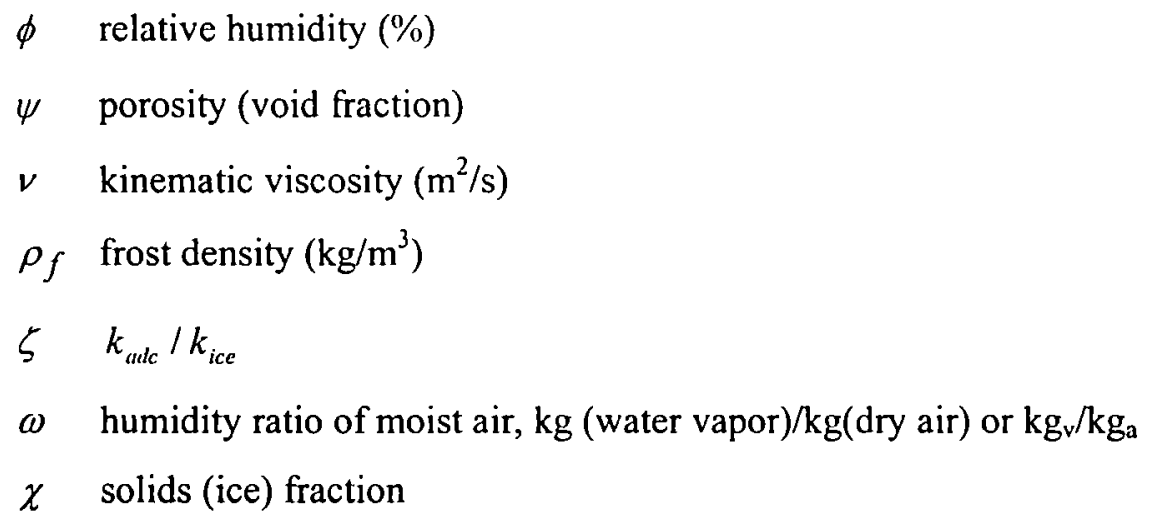

\section{Subscripts}

0 reference

1 continuous medium (stagnant gas)

2 solid particle (dispersed)

$\infty \quad$ ambient (freestream)

a dry air

c eddy convection, critical

d diffusion

$e \quad$ effective medium

$f$ frost

$m$ melting

$s \quad$ frost surface

$t$ total (ambient)

$v \quad$ water vapor

\section{Introduction}

Frost formation represents an important consideration in cryogenics, refrigeration, aerospace, meteorology and various process industries. Processes involving simultaneous heat transfer and frost formation are occasioned in gas coolers, refrigerators, regenerators, freeze-out purification of gases, cryopumping, and the storage of cryogenic liquids.

In reality, frost offers significant thermal resistance to heat transport in heat exchangers, and increases the pressure drop in channels by flow restriction. Frost/icing on aircraft wings 
causes significant aerodynamic penalties in lift and drag, leading to a decrease in lift and an increase in drag. Frost/ice formation on cold fuel/oxidizer tanks and other components may cause debris concerns when it is shed on critical components of launch vehicles. These applications call for an accurate prediction of frost growth, frost density, frost surface temperature, and total heat flux. A fundamental understanding of the nature of frost formation and simultaneous heat and mass transfer during frost growth is thus of great practical importance.

Frost forms when moist (humid) air comes in contact with a cold surface whose temperature is less than the freezing temperature of water $(273 \mathrm{~K})$, and is less than the dew point temperature, so that water vapor directly passes from a gaseous state to a solid state. A schematic of the frost layer is shown in Fig. 1. During frost formation, a portion of the total mass flux of water vapor diffuses through the frost layer, and undergoes phase transformation to ice which deposits on the existing frost crystals, resulting in frost densification (Jones and Parker [1]; Na and Webb [2]). The remainder of vapor mass flux freezes at the frost surface, and serves to increase the frost thickness. A review of frost formation in simple geometries (flat plates, parallel plates, cylinders, and annuli) was provided by O'Neal and Tree [3].

Experimental studies for frost formation on flat surfaces were published by various investigators; see Jones and Parker [1], Yonko and Sepsy [4], Östin and Anderson [5], Lee et al. [6,7], Cheng and Wu [8], Hermes et al. [9] among others. These studies suggest that during frost formation, frost thickness, frost surface temperature, frost density, and frost thermal conductivity all increase continuously. Both the density and the thermal conductivity are found to increase by an order of magnitude. As the frost layer thickens, the insulating effect of the frost layer predominates resulting in an increased thermal resistance of the frost layer and a decrease in heat transfer rate (Sherif et al. [10]). Measurements also reveal that the frost growth, densification and heat flux depend on a number of parameters such as frost density, frost surface temperature, plate surface temperature, and environmental parameters (air humidity $\omega_{\infty}$, air velocity $u_{\infty}$, air temperature $T_{\infty}$, etc.). Experiments by Östin and Anderson [5] and others suggest that the frost growth depends strongly on the cold plate temperature and the air humidity.

A number of theoretical models for frost formation on flat surfaces have been proposed for frost formation on flat surfaces. Notable among these models include those of Brian et al. 
[11,12], Jones and Parker [1], Sami and Duong [13], Sherif et al. [10], Tao et al. [14], Sahin [15], Le Gall et al. [16], Lee et al. [6], Cheng and Cheng [17], Na and Webb [2], Hermes et al. [9]. These models differ primarily in the treatment of frost density and thermal conductivity correlations and/or models and of mass diffusion within the frost layer. A comprehensive review of various theoretical models is provided by Tao et al. [14].

Notwithstanding the appearance of a large number of articles on frost growth measurements and modeling, there exist some inconsistencies and uncertainties primarily with regard to the role of air velocity and air temperature on frost growth and densification. Yonko and Sepsy [4] report that for flat surfaces even though increasing air velocity has no appreciable effect on frost thickness, the frost density is considerably increased. Data by Lee et al. [6] for flat plates suggest that increasing air velocity slightly increases the frost thickness, but changes the frost surface temperature (and thus frost density) appreciably. Measurements by Shah [18] on a circular plate indicate that higher Reynolds numbers and/or higher gas temperatures yield higher frost density and a decrease in frost thickness (Sami and Duong [13]). Data by Cheng and Wu [8] for flat plates indicate that increases in air velocity or air temperature resulted in little change in frost thickness but produced a denser frost layer on the basis of photographic (visual) examination.

In view of the aforementioned uncertainties in frost formation, it is evident that a more detailed understanding of the effects of frost parameters on the frost growth and densification is requisite. It is the purpose of this work to further clarify the role of air velocity and air temperature on the frost growth and densification processes. This objective is carried out with the aid of a one-dimensional theoretical model proposed to predict the frost growth and densification in laminar flow over flat surfaces. Improved formulations for frost density and frost conductivity valid for a wide range of conditions are incorporated. The validity of the proposed model will be assessed by comparison with measurements frost parameters including frost growth, frost surface temperature, frost density and frost heat flux as reported by various investigators covering a range of test conditions including cold plate temperature, air humidity, air velocity and air temperature. 


\section{Proposed Model}

In the present work, we propose a one-dimensional model for frost growth and densification along the lines of Jones and Parker [1] and Cheng and Cheng [17]. Improved formulations of frost density and thermal conductivity, applicable for a wide range of frost circumstances, are incorporated, and this marks an important difference between the present model and those of other investigators.

\subsection{Physical Assumptions}

The following physical assumptions are made in the present analysis:

(i) Heat and mass diffusion within the frost layer are assumed quasi-steady and onedimensional.

(ii) The frost layer grows in a direction normal to the cold plate surface with uniform frost thickness along the plate length.

(iii) Frost density and thermal conductivity are independent of frost thickness, and represent values averaged over the frost layer thickness. Thus at any instant, they are thus assumed uniform within the frost layer. Measurements by Brian et al. [12] suggest that at any instant during frost growth density variations within the frost layer are not significant.

(iv) The air pressure is uniform in the airstream and within the frost layer. Hermes et al. [9].

(v) The Lewis analogy for heat and mass transfer is applicable, and Lewis number of unity is considered. Measurements and analysis by Lee et al. [6] indicate that Lewis number increases with air velocity and air humidity, and is in the range of 0.7 to 1.0 .

(vi) Both the heat and mass transfer coefficients at the frost surface are considered constant.

(vii) The gas spaces in the frost layer are small enough that heat transfer by natural convection within the frost layer is negligible (Woodside [19]). Thermal radiation within the frost layer is negligible, considering that the frost temperatures are low (Dietenberger [20]). (viii) The total gas pressure is constant within the frost layer, and is equal to the atmospheric pressure (Le Gall et al. [16)).

(ix) Soret and Dufour effects are negligible (Le Gall et al. [16]).

(x) The local humidity of air in the frost layer corresponds to saturation humidity at that temperature (thermodynamic equilibrium). 
(xi) It is also assumed that at the frost surface the water vapor is saturated. Strictly speaking this assumption is somewhat tenuous, although many frost growth models consider this assumption. Detailed investigations by $\mathrm{Na}$ and $\mathrm{Webb}[2]$ indicate that water vapor is generally supersaturated at the frost surface rather than saturated, leading to appreciable overprediction of the mass transfer rate of water vapor onto the frost surface. The supersaturation degree (measure of departure of the actual water vapor pressure at the frost surface to the saturated water vapor pressure at the frost surface) is strongly dependent on the surface energy, which is a function of the surface coating governing the contact angle. In view of the absence of such information in reported experimental data, we follow for the present purposes the simplifying assumption of saturated vapor condition at the surface.

\subsection{Frost Density and Effective Thermal Conductivity}

The prediction of frost growth requires information concerning the average frost density and effective frost thermal conductivity, both of which depend on the porosity of the frost layer. The frost porosity $\psi$ is directly related to the frost density $\rho_{f}$ by the relation

$\psi=\left(1-\rho_{f} / \rho_{\text {ice }}\right) /\left(1-\rho_{g} / \rho_{\text {ice }}\right)$

where $\rho_{\text {ice }}$ is the density of ice (usually taken as $917 \mathrm{~kg} / \mathrm{m}^{3}$ ), and $\rho_{g}$ the density of air-vapor mixture. The porosity is related to the solids (ice) fraction $\chi$ by the relation $\chi=1-\psi$

A detailed review of frost density and thermal conductivity correlations (and their range of applicability) is provided by Tao et al. [14]. ONeal and Tree [3], Shin et al. [21], and Yang and Lee [22] presented a comprehensive list of the correlations for the effective thermal conductivity of frost.

\subsubsection{Frost Density}

Recently, the author [23] reviewed the existing data and correlations for frost density, and proposed a new and improved correlation in terms of dimensionless frost surface temperature and flow Reynolds number for application to laminar forced flow over flat surfaces. This correlation is based on simultaneous measurements of frost density and frost surface temperature and is shown to be valid over a broad range of frost density, and is expressed by 
$\frac{\rho_{f}}{\rho_{\text {ice }}}=0.5 \theta \exp \left\{-[0.376+1.5(1-\theta)]\left(1-\xi^{0.5}\right)\right\}$

where

$\theta=\left(T_{f s}-T_{w}\right) /\left(T_{m}-T_{w}\right), \quad \xi=\operatorname{Re} / \operatorname{Re}_{c}$

In the preceding equation, $\theta$ is the dimensionless frost surface temperature, and $\operatorname{Re}_{c}$ is the critical Reynolds number for laminar-turbulent transition. The Reynolds number is defined by

$\operatorname{Re}=u_{\infty} L / \nu$

where $L$ is the characteristic plate length, $u_{\infty}$ is the air velocity, and $v_{\infty}$ is the kinematic viscosity of the air. Fig. 2 (adapted from [23]), displays the variation of frost porosity and density as a function of dimensionless frost surface temperature with Reynolds number as a parameter. This model was validated over the full range of frost surface temperature. Note that the widely used correlation of Hayashi et al. [24] expresses frost density dependent on frost surface temperature only, and is known to considerably overpredict the frost density at relatively high frost surface temperatures close to the melting temperature [14].

\subsubsection{Effective Frost Thermal Conductivity}

The effective thermal conductivity of frost $k_{f}$ is obtained from the work of the author [25] on the basis of a porous packed bed model of Zehner-Schlunder [26] considering a unit cell approach and one-dimensional heat flow (see Hsu et al. [27], Cheng and Hsu [28]):

$\frac{k_{f}}{k_{\text {cdd }}}=1-\sqrt{1-\psi}+\frac{2 \sqrt{1-\psi}}{1-\zeta B}\left[\frac{(1-\zeta) B}{(1-\zeta B)^{2}} \ln \left(\frac{1}{\zeta B}\right)-\left(\frac{B+1}{2}\right)-\frac{B-1}{1-\zeta B}\right]$

where

$\zeta=k_{\text {sdc }} / k_{\text {ice }}$

In the preceding equations, $k_{\text {adc }}$ denotes the effective (stagnant) thermal conductivity of entrapped air considering mass diffusion and eddy convection. The shape factor $B$ is related to the porosity $\psi$ (defined by Eq. 1) by the relation

$B \approx C[(1-\psi) / \psi]^{m}$ 
with $m=10 / 9$. The constant $C$ is taken as 2.5 for cylindrical particles (Zehner-Schlunder [26]), which were found to represent frost structure and resulting frost thermal conductivity satisfactorily [25]. A detailed comparison of Zehner-Schlunder model with data (for spherical particles) for ice to air thermal conductivity ratio ranging from 8 to 1200 and for various values of solids fraction was recently presented by the author [29].

In the presence of mass diffusion and eddy convection, the effective thermal conductivity of air $k_{\text {culc }}$ is expressed as (Kandula [25]) $k_{\text {tudc }}=k_{a}+k_{d}+k_{c}$

where $k_{a}$ is the molecular thermal conductivity of air, $k_{d}$ is the contribution of mass diffusion to the effective thermal conductivity of air, and $k_{c}$ denotes the contribution of eddy convection to the effective conductivity of air.

The mass diffusion contribution $k_{d}$ Eq. (4) is obtained as [25]

$$
k_{d}=L_{s v}^{2} \frac{D\left(M_{a} / M_{v}\right)}{R_{v}^{2} T_{f}^{3}} p_{v 0} \exp \left[\frac{L_{s v}}{R_{v}}\left(\frac{1}{T_{0}}-\frac{1}{T_{f}}\right)\right]
$$

In the preceding equation, $D$ is the mass diffusivity of water vapor, $L_{s v}$ is the latent heat of sublimation, $M_{a}, M_{f}$ denote the molecular weights of air and water vapor respectively, $p_{v 0}$ is the partial pressure of water vapor at reference temperature $T_{0}, R_{v}$ is the gas constant for water vapor, and $T_{f}$ is the frost temperature.

The effect of eddy convection [30] prevalent in the air pockets is shown to be satisfactorily represented by the condition [25] $k_{c} / k_{a} \approx 1$

From a more fundamental consideration the effects of eddy convection are intimately related to the phenomenon of thermal dispersion (see Cheng and Vortmeyer [31]; Hsu and Cheng [32]). Convection in variable porosity media, including channeling effects, were considered by Vafai [33].

Thus the effective thermal conductivity of frost is obtained from Eqs. (3a-3f). Fig. 3 (adapted from [25]) shows a comparison of the predicted thermal conductivity with the wellestablished correlations of Sturm et al. [34], Van Dusen [35], and Östin and Anderson [5]. More detailed comparisons of the predicted thermal conductivity with the measurements of 
Pitman and Zuckerman [36], Brian et al. [36] and others at various temperatures are presented in the author's work [25].

\subsection{Governing Equations and Boundary Conditions}

\subsubsection{Governing Equations}

An energy balance for an elemental frost thickness in the interior of the frost layer (considering latent heat transport from the water vapor) can be expressed as [1], see Fig. 1):

$k_{f} \frac{d^{2} T}{d x^{2}}=L_{s v} \frac{d \dot{m}_{x}}{d x}$

where $\dot{m}_{x}$ stands for the local mass flux of water vapor in the $x$ direction (normal to the plate). The quantity $\dot{m}_{x}$ is given by the mass diffusion equation

$$
\dot{m}_{x}=-D \frac{d \rho_{v}}{d x}
$$

where $\rho_{\nu}$ stands for the local density of water vapor in the frost layer, so that

$$
\frac{d \dot{m}_{x}}{d x}=-D \frac{d^{2} \rho_{v}}{d x^{2}}
$$

\subsubsection{Boundary and Initial Conditions}

\section{a. Mass Flux at the Frost Surface}

The total mass flux of water vapor transferred from moist air to the frost surface can be written as

$\dot{m}_{t}=h_{m}\left(\omega_{a}-\omega_{s}\right)$

where $h_{m}$ denotes the convective mass transfer coefficient. The quantities $\omega_{a}, \omega_{s}$ are respectively the humidity ratios in the atmospheric air and at the frost surface. Eq. (5a) can be recast as (Jones and Parker [1])

$$
\begin{aligned}
& \dot{m}_{t}=\frac{d}{d t}\left(x_{s} \rho_{f}\right)=\rho_{f} \frac{d x_{s}}{d t}+x_{s} \frac{d \rho_{f}}{d t}=\dot{m}_{e}+\dot{m}_{d} \\
& \dot{m}_{e}=\phi_{f} d x_{s} / d t, \quad \dot{m}_{d}=x_{s} d \rho_{f} / d t
\end{aligned}
$$

Eq. (5b) physically implies that a portion of the total mass flux of water vapor is diffused into the existing frost layer before it freezes, and serves to increase the frost density. The 
remainder of this vapor is transported to the frost surface and freezes at the frost surface, and serves to increases the frost layer thickness (Jones and Parker [1]; Na and Webb [2]).

\section{b. Heat Flux at the Frost Surface}

The total heat(energy) transferred from the air to the frost surface is comprised of two components: sensible heat transfer (by convection) by virtue of the temperature difference, and the latent heat of sublimation due to humidity difference. Mathematically,

$q_{\mathrm{t}}=q_{\mathrm{sen}}+q_{\mathrm{lat}}$

where

$q_{\mathrm{sen}}=h_{c}\left(T_{a}-T_{f s}\right) \quad q_{\mathrm{lat}}=\dot{m}_{\mathrm{t}} L_{s v}$

In the preceding equation, $\dot{m}_{1}$ is given by Eq. $(5 \mathrm{~b})$, and $h_{c}$ is the convective heat transfer coefficient. Eq. (6a) can be recast as

$q_{1}=\left[h_{c}\left(T_{a}-T_{s}\right)+\rho_{f} L_{s v} \frac{d x_{s}}{d t}\right]+x_{s} L_{s v} \frac{d \rho_{f}}{d t}$

The quantity in the parenthesis represents the energy crossing the frost surface by conduction (Cheng and Cheng [17), so that

$q_{\text {cond }}=-k_{f}\left(\frac{d T}{d x}\right)_{s}=-\left[h_{c}\left(T_{a}-T_{s}\right)+\rho_{f} L_{s v} \frac{d x_{s}}{d t}\right]$

c. Temperature Boundary Conditions at the Wall and the Frost Surface

The boundary temperatures are prescribed as

$T=T_{w} \quad x=0$

$T=T_{f s} \quad x=x_{s}$

\section{d. Initial Condition}

The initial condition is specified by the requirement that the frost thickness is zero. Thus

$x_{s}=0 \quad t=0$

\subsection{Temperature Distribution in the Frost Layer}

By virtue of the assumption that the frost density remains uniform across the frost layer thickness, the amount of water vapor being frozen in the interior must be the same at all locations in the frost layer (Jones and Parker [1]). Consequently, Eq. (4c) becomes 
$\frac{d \dot{m}_{x}}{d x}=\frac{\dot{m}_{d l}}{x_{s}}$

Thus Eq. (4a) governing the temperature field is expressed by

$k_{f} \frac{d^{2} T}{d x^{2}}=-L_{s v}\left(\frac{\dot{m}_{d}}{x_{s}}\right)$

Substituting for $\dot{m}_{d}$ from Eq. (5c), and integrating twice with the appropriate boundary conditions (Eqs. 6d, 7a and 7b), we finally arrive at the temperature distribution in the frost layer as follows:

$$
\begin{aligned}
& T=T_{w}+c_{1} x+c_{2} x^{2} \\
& c_{1}=\frac{L_{s v}}{k_{f}}\left[h_{c}\left(T_{a}-T_{s}\right)+h_{m}\left(\omega_{a}-\omega_{s}\right)\right] \\
& c_{2}=-\frac{L_{s v}}{k_{f} x_{s}}\left[h_{m}\left(\omega_{a}-\omega_{s}\right)-\rho_{f} \frac{d x_{s}}{d t}\right]
\end{aligned}
$$

The temperature at the frost surface corresponding to $x=x_{s}$ can at once be obtained from Eq. (11a) as follows (Cheng and Cheng [17]):

$$
T_{s}=T_{w}+\left(\frac{x_{s}}{k_{f}}\right) h_{c}\left(T_{a}-T_{s}\right)+\frac{1}{2}\left(\frac{x_{s} L_{s v}}{k_{f}}\right)\left[h_{m}\left(\omega_{a}-\omega_{s}\right)+\rho_{f} \frac{d x_{s}}{d t}\right]
$$

\subsection{Frost Layer Growth Rate}

From Eqs. (5a) and (5b), the frost layer growth rate is obtained as

$$
h_{m}\left(\omega_{n}-\omega_{s}\right)=\rho_{f} \frac{d x_{s}}{d t}+x_{s} \frac{d \rho_{f}}{d t}
$$

On the basis of the correlation for the frost density (Eq. 2), we have

$$
\rho_{f} / \rho_{\text {ice }}=0.5 \theta \exp \left\{\left[c_{1}+c_{2}(1-\theta)\right]\left(1-\xi^{0.5}\right)\right\}
$$

Thus

$$
\frac{d \rho_{f}}{d t}=\frac{d \rho_{f}}{d \theta} \frac{d \theta}{d T_{f s}} \frac{d T_{f s}}{d x_{s}} \frac{d x_{s}}{d t}
$$

Performing the differentiation and rearranging, we finally obtain that 


$$
\frac{d x_{s}}{d t}=\frac{h_{m t}\left(\omega_{n}-\omega_{s}\right)}{\rho_{f}\left\{1+x_{s}\left[c_{2}\left(1-\xi^{0.5}\right)+\frac{1}{\theta}\right] \frac{1}{\left(T_{m}-T_{w}\right)} \frac{d T_{f s}}{d x_{s}}\right\}}
$$

\subsection{Heat and Mass Transfer Coefficients}

The convective heat transfer coefficient $h_{c}$ for laminar force flow over a flat plate is determined from the well-known correlation (Kays and Crawford [37])

$N u=0.664 \mathrm{Re}^{1 / 2} \operatorname{Pr}^{1 / 3}$

where the Nusselt number $N u$ and the Prandtl number Pr are defined by

$$
N u=h_{c} L / k, \quad \operatorname{Pr}=c_{p} \mu / k
$$

and $k$ refers to the thermal conductivity of air The fluid properties for the boundary layer are evaluated at the average film temperature.

The convective mass transfer coefficient $h_{m}$ is obtained on the basis of Chilton-Colburn analogy between heat and mass transfer (Eckert and Drake [38]), which is found to be applicable under frosting conditions ( $\mathrm{O}^{\prime} \mathrm{Neal}$ and Tree [5]):

$\operatorname{Sh} L e^{2 / 3}=N u$

where the Sherwood number Sh and the Lewis number Le are defined by

$S h=h_{m} L / D, \quad L e=\alpha / D=\operatorname{Pr} / S c$

In the preceding equation, $\alpha=k / \rho c_{p}$ represents the thermal diffusivity, $S c=D / v$ is the

Schmidt number, and $c_{p}$ is the specific heat of moist air. Consequently we have

$h_{m}=h_{c} /\left(\rho c_{p} L e^{2 / 3}\right)$

with specific heat of moist air quantity $c_{p}$ determined from the mixture relation

$c_{p}=c_{p a}+\omega_{a} c_{p}$

A value of $L e=1$ is considered in the present analysis. 


\subsection{Thermophysical Properties}

The thermal conductivity of air is calculated as (Rohsenow and Hartnett [42]; Dietenberger [20])

$k_{\text {air }}=2.646 \times 10^{-13}\left[\frac{T^{1 / 2}}{1+(245 / T) 10^{12 / T}}\right] \frac{\mathrm{W}}{\mathrm{m} \cdot \mathrm{K}}$

where $T$ is in degrees Kelvin. The thermal conductivity of ice is obtained from the relation (Dillard and Timmerhaus [43]; also Dietenberger [20])

$k_{\text {ice }}=630 / T \mathrm{~W} /(\mathrm{m} . \mathrm{K})$

where $T$ is the absolute temperature (degrees $\mathrm{K}$ ).

The mass diffusivity is determined from (Pruppachar and Eklett [39]) as

$D=2.11 \times 10^{-5}\left(T_{f} / T_{0}\right)^{1.94} \mathrm{~m}^{2} / \mathrm{s}$

where $T_{f}$ is the frost temperature in degrees Kelvin, and $T_{0}$ the reference temperature (273.15 K).

The latent heat of sublimation of ice is determined from (Mago et al. [40])

$L_{f v}=\{-0.1083[1.8(T-273.16)+32]+2833\} \mathrm{kJ} / \mathrm{kg}$

where $T$ is in degrees Kelvin.

The humidity ratio of air at the frost surface $\omega_{s}$ is determined from (Kays and Crawford [37]):

$\omega_{s}=0.622 p_{v s} /\left(p_{t}-p_{v s}\right)$

where $p_{1}$ is the total pressure in atm, $p_{v s}$ is the saturation vapor pressure corresponding to the frost surface temperature $T_{f s}$. The vapor pressure $p_{v s}$ is evaluated from standard curve-fits (Mago et al. [40]; Flatau [41]).

\section{Numerical Solution}

The frost growth and frost surface temperature are obtained by numerically integrating Eq. (13d) in conjunction with Eqs. (6), (12) and (13b), considering the initial condition expressed by Eq. (8). The equation for the frost surface temperature is implicit. Initially a frost surface temperature at $t+\Delta t$ is guessed, and a bisection method is used to iterate for the frost surface temperature. A time step of $\Delta t=0.1 \mathrm{sec}$ is chosen. For stability of computation, 
a very small value of $x_{s}=10^{-5} \mathrm{~m}$ is considered. The calculation is terminated when the frost surface reaches the melting temperature. From the calculated first surface temperature, the frost density is evaluated with the aid of Eq. (2). The heat flux values (sensible, latent and total) are subsequently obtained from Eq. (6a) and (6b).

The numerical solution is found to be robust over a wide range of test parameters considered in the present investigation.

\section{Results and Comparison}

The validity of the proposed model is tested by a comparison of the predictions of frost properties with test data from various investigators comprising a range of frost conditions (cold plate temperature, ambient air humidity, air velocity, and air temperature). All the test data chosen for comparison correspond to the geometry of flat surfaces. Although frost thickness is measured in every test data, only certain data sets contain frost surface temperature, frost density, and heat flux. Note that accurate frost surface temperature measurement is relatively difficult. In all the comparisons, a value of $\operatorname{Re}_{c} \approx 10^{5}$ appearing in the frost density correlation, Eq. (2), has been considered for the model predictions [23].

\subsection{Comparison with Data of Yonko and Sepsy [4]}

Figure $4 a-4 c$ displays a comparison of model predictions for frost thickness with the experimental data of Yonko and Sepsy [4] on an aluminum plate. The test plate dimensions are $L=0.3398 \mathrm{~m}, W=0.1905 \mathrm{~m}$, and $b=0.0222 \mathrm{~m}$. The frost thickness is measured to within $0.13 \mathrm{~mm}$ with the aid of a micrometer working against a spring-loaded cross-slide. Uncertainty in the measured frost thickness is about $0.13 \mathrm{~mm}$. These data represent one of the early measurements on frost formation, and have been very widely considered in the comparison of many theoretical models of frost growth. No data on frost surface temperature, frost density and heat flux were reported.

Figure 4a illustrates the comparison of frost growth for changing wall temperatures. Three sets of data are considered here: Run \#13: $T_{\infty}=295.1 \mathrm{~K}, T_{w}=245.5 \mathrm{~K}, u_{\infty}=2.96 \mathrm{~m} / \mathrm{s}$, $\omega_{o}=0.0108 \mathrm{~kg} / \mathrm{kg}_{\mathrm{a}}\left(\phi_{\%}=65.8 \%\right)$; Run \#14: $T_{\infty}=294.9 \mathrm{~K}, T_{w}=254.9 \mathrm{~K}, u_{\infty}=2.57 \mathrm{~m} / \mathrm{s}$, $\omega_{\infty}=0.0106 \mathrm{~kg} / \mathrm{kg}_{\mathrm{a}}\left(\phi_{x}=64.4 \%\right) ;$ Run \#15T $T_{\infty}=295.8 \mathrm{~K}, T_{w}=264.7 \mathrm{~K}, u_{\infty}=2.92 \mathrm{~m} / \mathrm{s}$, 
$\omega_{\infty}=0.0117 \mathrm{~kg}_{\mathrm{v}} / \mathrm{kg}_{\mathrm{a}}\left(\phi_{\infty}=66.7 \%\right)$. The duration of the test is $150 \mathrm{~min}$ for Run $\# 13$, and 175 min for Runs \#14 and 15. Both the data and the model exhibit a monotonic increase in frost thickness and a decrease in frost growth rate with elapsed time. The relatively high frost growth rate is attributed to a thinner frost layer endowed with a lower thermal resistance. The model describes the experimental trend that the frost thickness increases as the wall temperature decreases as a consequence of increased heat transfer rate. The data suggest that at $150 \mathrm{~min}$, the frost thickness is nearly doubled (110\%) as the wall temperature increases by $20{ }^{\circ} \mathrm{K}$ from $246 \mathrm{~K}$ to $265 \mathrm{~K}$, as remarked by Yonko and Sepsy [4]. For $T_{w}=255 \mathrm{~K}$, excellent agreement is achieved between the theory and the data for the entire duration. However there is some overprediction at $T_{w}=265 \mathrm{~K}$ and underprediction at $T_{w}=245 \mathrm{~K}$. It is believed that uncertainties in the frost density model in the crystal growth period (where the frost density is low) could lead to errors in the predicted frost thickness, even though the growth rates in the DBG (Densification and Bulk Growth) period are satisfactorily predicted. The predicted frost surface temperature and frost density are found to increase with an increase in wall temperature, as is to be expected.

Figure $4 \mathrm{~b}$ shows a comparison of the model with measurements to reflect the effect of relative humidity. Two sets of data are considered here: Run \#7: $T_{\infty}=294 \mathrm{~K}, T_{w}=245 \mathrm{~K}$, $u_{\infty}=1.26 \mathrm{~m} / \mathrm{s}, \omega_{\infty}=0.009 \mathrm{~kg}_{\mathrm{v}} / \mathrm{kg}_{\mathrm{a}}\left(\phi_{\infty}=55.2 \%\right) ; \operatorname{Run} \# 10: T_{\infty}=296 \mathrm{~K}, T_{w}=245 \mathrm{~K}, u_{\infty}=$ $1.37 \mathrm{~m} / \mathrm{s}, \omega_{\infty}=0.0141 \mathrm{~kg}_{\mathrm{v}} / \mathrm{kg}_{\mathrm{a}}\left(\phi_{\infty}=78.1 \%\right.$ ). The test duration for Run \#7 is $200 \mathrm{~min}$, and that for Run \#10 is 140 min. The model is shown to describe the experimental trend of increasing frost thickness with increasing humidity ratio as a result of increased mass transfer rate. Satisfactory agreement between the prediction and the data is noticed for the two humidity ratios considered. As remarked in Yonko and Sepsy [4], a $42 \%$ increase in the relative humidity (from 55.2 to $78.1 \%$ ) increased the frost thickness by roughly $28 \%$. The predicted surface temperature and frost density are found to increase with an increase in the humidity ratio, as is to be expected.

A comparison of the model predictions with the data for frost thickness is presented in Fig. $4 \mathrm{c}$ to highlight the influence of air velocity. Two sets of data are considered here for comparison: Run \#9: $T_{\infty}=294 \mathrm{~K}, T_{w}=245 \mathrm{~K}, u_{\infty}=1.28 \mathrm{~m} / \mathrm{s}, \omega_{\infty}=0.0010 \mathrm{~kg}_{\mathrm{v}} / \mathrm{kg}_{\mathrm{a}}\left(\phi_{\mathrm{s},}=\right.$ $65.2 \%)$; Run \#15: $T_{\infty}=296 \mathrm{~K}, T_{w}=265 \mathrm{~K}, u_{\infty}=2.92 \mathrm{~m} / \mathrm{s}, \omega_{\infty}=0.0117 \mathrm{~kg} / \mathrm{kg}_{\mathrm{a}}\left(\phi_{\mathrm{x}}=\right.$ 
$66.7 \%$ ). The data indicate that, for the conditions considered, air velocity on frost thickness has no appreciable effect on frost thickness as the air velocity is nearly doubled. The data also reveal that (excepting for the early crystal growth period) there appears to be a crossover point in time for the frost thickness as the air velocity increases: as the air velocity is increased, the frost thickness is initially reduced, but later slightly increased at large times. This behavior is clearly reproduced by the present model. Yonko and Sepsy [4] point out that although the data for frost thickness at the two air velocities are nearly identical, the frost densities for these test runs were quite different, although the density data are not reported. Physically, higher air velocity enhances heat and mass transfer to the frost surface. An increase in frost density with a nearly constant frost thickness implies that more vapor mass is diffused through the frost layer, thus densifying the frost layer.

In order to clarify this matter theoretically the role of increased air velocity on frost densification, Fig. $4 \mathrm{~d}$ shows the predicted frost densities for Run \#9 and 15. The model indeed predicts that the frost densities are considerably different for the two air velocities under consideration, in accordance with the observations of Yonko and Sepsy [4]. To the author's knowledge, such a clarification with regard to the role of air velocity on frost densification has not been previously exemplified well from a theoretical point of view.

From the foregoing comparisons, it is evident that the plate surface temperature has larger effect on frost thickness than the relative humidity, while both the plate temperature and the relative humidity have greater effect than the air velocity. These experimental facts are satisfactorily described by the present model.

\subsection{Comparison with Data of Cheng and $W_{u}[8]$}

The effects of air velocity and air temperature on frost thickness and frost density are illuminated in Fig. 5 by a comparison of the model predictions with the experimental data of Cheng and $\mathrm{Wu}[8]$. The square copper plate has dimensions of $L=W=0.056 \mathrm{~m}$, and a thickness $b=6 \mathrm{~mm}$. The test duration is $30 \mathrm{~min}$, and thus correspond to early stages of frost formation with a high resolution in time. Frost thickness is measured by a microscopic image system (registering data every five seconds). The uncertainty in the measured frost thickness is stated as $0.007 \mathrm{~mm}(0.3 \%)$. No data on frost surface temperature, frost density, and heat flux are reported. 
Figure 5a shows the test data of Cheng and Wu [8] exhibiting the effect of air velocity on the frost thickness. Two sets of data are chosen here: Set \#8a: $T_{\infty}=300.8 \mathrm{~K}, T_{w}=262.8$ $\mathrm{K}, u_{\infty}=4.2 \mathrm{~m} / \mathrm{s}, \phi_{\infty}=42 \%$; Set $\# 8 \mathrm{~b}: T_{\infty}=300.8 \mathrm{~K}, T_{w}=262.8 \mathrm{~K}, u_{\infty}=6.0 \mathrm{~m} / \mathrm{s}, \phi_{\infty}=42 \%$. The data suggest that increasing the air velocity (by $43 \%$ from $4.2 \mathrm{~m} / \mathrm{s}$ to $6 \mathrm{~m} / \mathrm{s}$ ) does not have an appreciable effect on frost thickness. Cheng and $\mathrm{Wu}[8]$ report that photographic (visual) examination indicated that denser frost prevailed at increased velocity. These experimental trends concerning the role of air velocity on frost thickness and frost density confirm those embodied in the data of Yonko and Sepsy [4], see Fig. 4c. The model predictions shown in Fig. $5 \mathrm{~b}$ are in accord with the test observations of Cheng and Wu [8] with regard to the frost thickness and frost density (model predicts at $t=30 \mathrm{~min}$ a density increase from $250 \mathrm{~kg} / \mathrm{m}^{3}$ to $300 \mathrm{~kg} / \mathrm{m}^{3}$ as the air velocity increased from $4.2 \mathrm{~m} / \mathrm{s}$ to $6.0 \mathrm{~m} / \mathrm{s}$ ).

Figure 5c presents the test data of Cheng and Wu [8] exhibiting the effect of air temperature on the frost thickness. Two sets of data are chosen here: Set \#6a: $T_{\infty}=296.5 \mathrm{~K}$, $T_{w}=261.9 \mathrm{~K}, u_{\infty}=2.3 \mathrm{~m} / \mathrm{s}, \phi_{\infty}=76 \%$; Set \#6b: $T_{\infty}=301.6 \mathrm{~K}, T_{w}=261.9 \mathrm{~K}, u_{\infty}=2.3 \mathrm{~m} / \mathrm{s}$, $\phi_{\infty}=76 \%$. The data suggest the frost thickness is rather insensitive to changes in air temperature (increase of $5 \mathrm{~K}$ ). Cheng and $\mathrm{Wu}[8]$ again report that photographic (visual) examination revealed that denser frost prevailed at increased air temperature. The model predictions shown in Fig. 5d suggest a slight increase in frost thickness (a $12 \%$ increase in frost thickness from $1.77 \mathrm{~mm}$ to $1.98 \mathrm{~mm}$ ) with increased air temperature (a $23 \%$ increase in air temperature relative to the melting temperature). The model concurs with the test observations with regard to the frost density, and suggests that at $t=30 \mathrm{~min}$, model predicts a density increase from $236 \mathrm{~kg} / \mathrm{m}^{3}$ to $300 \mathrm{~kg} / \mathrm{m}^{3}$ as the air temperature is increased from $296.5 \mathrm{~K}$ to $301.6 \mathrm{~K}$. Physically, for a constant relative humidity of air ( $\phi_{\infty}=$ constant), an increase in air temperature manifests itself in an increase in the moisture content of air (Cheng and $\mathrm{Wu}[8]$ ). This situation will likely lead to increases in frost thickness and frost density, as the theory suggests.

Figure 5e shows a comparison of the model predictions with the measurements of Cheng and $\mathrm{Wu}[8]$ for frost thickness, indicating the combined role of relative humidity and air velocity. Two sets of data were considered: Set $\# 11: T_{\infty}=300 \mathrm{~K}, T_{w}=266 \mathrm{~K}, \phi_{*}=41 \%$, and $u_{\infty}=4.2 \mathrm{~m} / \mathrm{s} ;$ Set \#12: $T_{\infty}=299.7 \mathrm{~K}, T_{w}=268 \mathrm{~K}, \phi_{s}=72 \%, u_{\infty}=6.1 \mathrm{~m} / \mathrm{s}$. For both sets of 
data, the model somewhat underpredicts the data by nearly a constant amount, independent of time during the frost layer growth period. As alluded to earlier, this difficulty is believed to arise due to the apparent inability of the model to accurately predict the relatively rapid frost growth rate in the early state of frost formation characterizing the crystal growth period. The result suggests that the frost thickness increases as the relative humidity increases, as was also observed in Fig. 4c. In the case of Set \#12, the data exhibit a step-wise (and cyclic) increase in frost thickness for times in excess of about $18 \mathrm{~min}$. This behavior was ascribed to the occurrence of melting visually observed at the frost surface (Cheng and $\mathrm{Wu}[8]$ ).

When the frost surface (air-frost interface) temperature approaches the freezing temperature, repeated cycles of melting and freezing occur (Sami and Duong [13]). This results in structural changes in the frost layer that tend to increase both the density and thermal conductivity with time without a proportional (corresponding) increase in the frost thickness. This phenomenon is more likely to occur in high humidity and/or high temperature environments than in low humidity and low temperature environments. In the latter case, the frost surface temperature will rise to a steady value below the melting point, such that the rate of frost deposition is balanced by the rate of sublimation from the frost (Sherif et al. [10]). Yonko and Sepsy [4] observe that in the test runs of high humidity and high plate temperature the frost surface temperature reaches the melting temperature within one to two hours after the commencement of the test.

Figure $5 \mathrm{f}$ shows the predicted variation of frost surface temperature for Set $\# 11$ and Set \#12. The frost surface is initially at the cold wall temperature and increases monotonically with time. No melting is predicted for Set $\# 11$, characterized by low humidity condition. In the case of Set $\# 12$ (comparatively high humidity), the model computation is terminated once melting occurs at about $25 \mathrm{~min}$. This prediction of the time for the approach of melting temperature is in reasonable agreement with the data for frost thickness, exhibiting the stepwise and cyclic variation with time commencing at about $20 \mathrm{~min}$. These results suggest that the model is capable of predicting the frost surface temperature satisfactorily. Since the effect of air velocity is relatively small (as noted in Fig. 4c), it is to be expected that the increase in frost thickness is primarily on account of an increase in the relative humidity, and thus the comparison in Fig. 5e serves to reflect primarily the role of relative humidity on frost thickness. 


\subsection{Comparison with Data of Lee et al. [6]}

Figures 6a-6d present a comparison of the model predictions with the test data of Lee et al. [6] exemplifying the role of air humidity and air velocity on frost thickness and frost surface temperature. Two sets of conditions are considered: Set \#1: $T_{\infty}=298.2 \mathrm{~K}, T_{w}=258.2$ $\mathrm{K}, u_{\infty}=1.0 \mathrm{~m} / \mathrm{s}, \phi_{\infty}=50 \%, 70 \%$ and $80 \%$. Set $\# 2: T_{\infty}=298.2 \mathrm{~K}, T_{w}=258.2 \mathrm{~K}, \phi_{x}=70 \%$, $u_{\infty}=0.5 \mathrm{~m} / \mathrm{s}$, and $1 \mathrm{~m} / \mathrm{s}$. The plate length $L=0.3 \mathrm{~m}$. The test duration is $120 \mathrm{~min}$. Digital micrometer is used for measuring the frost thickness, and frost surface temperature is measured with infrared radiation surface temperature detector assuming that emissivity of the frost surface is 0.94 . The uncertainty in measured frost thickness is reported as $\pm 0.1 \mathrm{~mm}$, and that in measured frost surface temperature as $\pm 0.5^{\circ} \mathrm{C}$. No data on frost density and heat flux are reported.

Figures $6 \mathrm{a}$ and $6 \mathrm{~b}$ display the comparisons of the model predictions with test data (Set \#1) for frost thickness and frost surface temperature signifying the role of relative humidity. Generally reasonable agreement is achieved between the model and the measurements for the frost thickness at the three values of $\phi_{\infty}=50,70$ and $80 \%$ (Fig. 6a), although it must be admitted that the model somewhat underpredicts the data. In the case of $\phi_{\infty}=50 \%$, the model satisfactorily predicts that data up to $t=90 \mathrm{~min}$, beyond which the data show a small jump in frost thickness. The model satisfactorily predicts the experimental trend that the frost thickness increases as the relative humidity increases, as is to be expected. Fig. $6 \mathrm{~b}$ suggests that the model describes the measured frost surface temperature reasonably well except for some overprediction in the case of $\phi_{\infty}=50 \%$ (where the data exhibit somewhat irregular behavior for times below about $40 \mathrm{~min}$ ). At $\phi_{\infty}=80 \%$, the measured frost surface temperature increases to about $-4{ }^{\circ} \mathrm{C}$, which is relatively close to the melting temperature. The model predicts the correct trend that the frost surface temperature increases with increasing relative humidity on account of increased mass transfer rate.

Figure $6 \mathrm{c}$ shows a comparison of the predictions with the test data for frost thickness illustrating the effect of air velocity. The measurements suggest that as the air velocity increases the frost thickness increases, with the data for $V=0.5 \mathrm{~m} / \mathrm{s}$ and $V=1 \mathrm{~m} / \mathrm{s}$ approach 
each other for times in excess of about 110 minutes. The model is seen to satisfactory represent the observed frost thickness. According to the model, the air velocity effect on frost thickness is not appreciable, as already noted in Figs. 4c, 5a and 5b.. Fig. 6d shows a comparison of the frost surface temperature. The model compares well with data for frost surface temperature for $u_{\infty}=0.5 \mathrm{~m} / \mathrm{s}$ and $1 \mathrm{~m} / \mathrm{s}$, considering the irregular behavior in the data for $u_{\infty}=0.5 \mathrm{~m} / \mathrm{s}$. The model predicts the correct trend that the frost surface temperature (and thus the frost density) increases as the air velocity increases. This is to be expected because as the velocity increases heat and mass transfer rates increase, resulting in frost densification, as alluded to earlier.

\subsection{Comparison with Data of Lee et al. [7]}

Figures $7 \mathrm{a}-7 \mathrm{~d}$ display respectively the comparison of the predictions with the measurements of Lee et al. [7] for frost thickness, frost surface temperature, frost density, and heat flux. The test conditions are: $T_{\infty}=288.2 \mathrm{~K}, T_{w}=258.2 \mathrm{~K}, \omega_{\infty}=0.00633 \mathrm{~kg} / \mathrm{kg}_{\mathrm{a}}$, and $u_{\infty}=2.5 \mathrm{~m} / \mathrm{s}$. The test plate has dimensions of $L=0.3 \mathrm{~m}$ and $W=0.15 \mathrm{~m}$. The thickness of the frost layer is measured by a digital thermometer, and the frost surface temperature is measured by an infrared thermometer. The frost density is measured by weighing the frost mass with the aid of a chemical balance and the known (measured) frost thickness at $t=15$, $30,60,90,120,150$ and $180 \mathrm{~min}$. The uncertainty in the measurements are: $5.57 \%$ in $x_{s}$, $4.36 \%$ in $T_{f s}, 6.94 \%$ in $\rho_{f}$ and $3.69 \%$ in the total heat flux $q_{\text {tot }}$. The temperature and humidity of the inlet/outlet air in the test section are measured by type-T thermocouples and humidity sensors respectively (Lee et al. [7]).

From Fig. 7a, it is evident that there is considerable deviation between the prediction and the data for frost thickness for times in excess of about $90 \mathrm{~min}$, with a maximum deviation 1 $\mathrm{mm}$ at $t=120 \mathrm{~min}$ ( $25 \%$ error), even though the predicted growth rate is seen to be reasonably satisfactory. This error is compared to the uncertainty in the measured frost thickness of $6 \%$. It is however noticed that there is considerable agreement between the theory and the data in the initial growth period $(t<30 \mathrm{~min})$.

The frost surface temperature prediction is seen to be satisfactory as evident from Fig. $7 \mathrm{~b}$. At $t=180 \mathrm{~min}$, the model prediction is within about $1.0^{\circ} \mathrm{C}$ of the test data. As pointed out in 
Lee et al. [7], there are very few experimental data for frost surface temperature reported in the literature on account of the difficulty of measurement with a reasonable accuracy. The surface temperature increases relatively rapidly during the early stage of frost growth where the frost layer grows fast, but the rate of increase in frost surface temperature diminishes with time as the frost growth rate decreases.

Figure $7 \mathrm{c}$ displays a comparison of the predicted frost density with the measurements. Excellent agreement is noted between the theory and experiments during the entire test period. The frost density increases rapidly in the early stage of frost growth (less than about $30 \mathrm{~min}$ ), and the rate of increase of frost density is small for times in excess of about 120 min. As the frost density is correlated with the frost surface temperature, a good agreement between the theory with the data for frost surface temperature also results in similar agreement in frost density prediction.

Figure 7d presents a comparison of the frost predictions with the measurements of sensible heat flux, latent heat flux and total heat flux (sensible and latent). The data suggest that the sensible heat flux is considerably larger than the latent heat flux (by a factor of about two), and decreases continuously during frost formation as the surface temperature of the frost layer increases with its growth (Lee et al. [7]). On the other hand, the latent heat flux remains fairly constant with time, following a small drop at the commencement of frost formation. The results also suggest that the total heat flux reduces from about $500 \mathrm{~W} / \mathrm{m}^{2}$ at $t=15 \mathrm{~min}$ to about $400 \mathrm{~W} / \mathrm{m}^{2}$ at $t=180 \mathrm{~min}$ (a $25 \%$ drop).

\subsection{Comparison with Data of Hermes et al. [9]}

Recently Hermes et al. [9] reported measurements of frost thickness, frost density and frost surface temperature. The measurements were performed on a square test plate with dimensions of $L=W=0.1 \mathrm{~m}$. Two separate sets of measurements were obtained for frost growth and frost density. The test conditions for the frost thickness measurement are : $T_{\infty}=$ $289.2 \mathrm{~K}$ and $295.2 \mathrm{~K}, T_{w}=257.2 \mathrm{~K}$ to $269.2 \mathrm{~K}, \phi_{x}=50 \%$ and $80 \%$, and $u_{\infty}=0.7 \mathrm{~m} / \mathrm{s}$ and $1.0 \mathrm{~m} / \mathrm{s}$. The test duration is $120 \mathrm{~min}$. The test conditions for frost density measurements are: $T_{\infty}=289.2 \mathrm{~K}$ and $295.2 \mathrm{~K}, T_{w}=258 \mathrm{~K}, 261 \mathrm{~K}, 265 \mathrm{~K}$ and $269 \mathrm{~K}, \phi_{\infty}=50 \%$ and $80 \%, u_{\infty}=$ $0.7 \mathrm{~m} / \mathrm{s}$, and $t=60 \mathrm{~min}$ and $120 \mathrm{~min}$. The frost thickness is measured by a digital camera in 
conjunction with image processing. The density (mass) is measured by an electronic scale. The surface temperature is measured by an infrared camera. The measurement uncertainties are: $\pm 5 \mu \mathrm{m}( \pm 2 \%)$ in frost thickness, $\pm 5 \%$ in frost density, and $\pm 0.2^{\circ} \mathrm{C}$ in frost temperature.

Figure 8 shows a comparison of the predictions with the test data of Hermes et al. [9] for frost thickness for various wall temperatures at $T_{\infty}=289 \mathrm{~K}, u_{\infty}=0.7 \mathrm{~m} / \mathrm{s}$ and $\phi_{\infty}=80 \%$. The present model favorably compares with the measurements for various wall temperatures, except for $T_{w}=257 \mathrm{~K}$ where the error is relatively large. Both the data and the model indicate that the frost growth increases with a decrease in the cold plate temperature, as is to be expected. It is noticed that in the early frost growth period, the predicted frost thickness generally exceeds the test data for relatively high wall temperatures, while for the low wall temperature the trend is opposite. This observation again suggests that that the early growth period is important for accurate frost growth prediction.

Table 1 shows a comparison of the predictions with the data of Hermes et al. [9] for frost thickness, frost surface temperature and frost density at $t=60$ and $120 \mathrm{~min}$, for $T_{\infty}=289 \mathrm{~K}$, $u_{\infty}=0.7 \mathrm{~m} / \mathrm{s}, \phi_{\infty}=50 \%$ and $80 \%$ and $T_{w}=15,-10$ and $-5{ }^{\circ} \mathrm{C}$. The results suggest that with a decrease in wall temperature, the frost thickness increases, while the frost surface temperature and the frost density decrease. This effect arises due to an augmentation in the supercooling degree that results in a higher overall mass flux and a lower frost density (Hermes [9]). It is also noticed form the data that as the relative humidity increases, the frost thickness increases with an accompanying increase in frost surface temperature and frost density. These trends are correctly reproduced by the model. In general, the model satisfactorily describes the data for frost growth, frost surface temperature and frost density for $t=60 \mathrm{~min}$ and $120 \mathrm{~min}$.

\section{Discussion}

It is pertinent to enumerate major differences between the present model and the existing models such as those of Jones and Parker [1], Cheng and Cheng [17], and Na and Webb [2]. Jones and Parker [1] consider that the energy crossing the frost surface by conduction

$q_{\text {cond }}=-k_{f}\left(\frac{d T}{d x}\right)_{s}=-\left[h_{r}\left(T_{a}-T_{s}\right)+\dot{m}_{c} L_{s v}\right]$ 
where $m$, is expressed by Eq. (5b). The present model considers Eq. (6d) instead, thus differing from Eq. (21) with regard to the second term on the right hand side. According to Cheng and Cheng [17], the consideration of Eq. (21) in the Jones and Parker model [1] could overestimate the latent energy released at the frost surface and leads to an undesired increase in frost surface temperature. Further, Jones and Parker [1] consider the thermal conductivity correlation due to Brian et al. [12].

The primary difference between the present model and that of Chang and Chang [17] lies in the expressions for the frost density and frost thermal conductivity, as alluded to before. Cheng and Cheng [17] incorporate the empirical correlation for frost density due to Hayashi et al. [24]:

$\rho_{f}=650 \exp \left[0.227\left(T_{f s}-273.15\right)\right.$

where $\rho_{f}$ is in $\mathrm{kg} / \mathrm{m} 3$, and $T_{f s}$ is in degrees Kelvin, which has a limited range of applicability, and depends on the frost surface temperature only. Also, in their model, the thermal conductivity correlation due to Brian et al. [12] is considered. Referring to the present model, improved formulations for frost density [23] and frost thermal conductivity [25], which are validated with experimental data over a broad range of frost conditions, are incorporated.

A key element of the $\mathrm{Na}$ and Webb model [2] is that the water vapor is supersaturated at the frost surface, rather than saturated. In the present model, it is assumed that the water vapor at the frost surface is saturated, as was done in many frost models. The importance of the supersaturation condition has been alluded to earlier in the section on assumptions, and such a condition needs to be considered in improving the accuracy of the predictions of frost growth and densification. Another feature of the advanced model due to $\mathrm{Na}$ and Webb [2] is that the model requires the solution of two partial differential equations for the frost thickness and frost density (considering frost density gradient within the frost layer), The differential equations require an initial condition for the frost density, which generally involves a trial and error approach. However in the present model, only an ordinary differential equation for the frost thickness is solved for, and requires no initial condition for frost density.

Although it would be useful to present detailed comparisons between the predictions of the present model with those of other models, such as those of $[1,2,17]$, for several sets of 
data covering a broad range of parameters, the author believes that such an undertaking calls for an elaborate effort, which is outside of the scope of the present investigation. The author hopes to accomplish such a comparison in a future investigation.

It is expected that the proposed model can be easily extended to include the effects of variable parameters (wall temperature, relative humidity of air, air temperature, and air velocity) to deal with important practical problems. In this connection, it may be pointed out that Ellgas and Pfitzner [44] recently modeled the pulsed injection of cryogenic hydrogen into humid air (complex configuration with unsteady flow) by coupling a simple onedimensional frost model to a commercial CFD code.

\section{Conclusions}

The proposed model frost growth and densification is shown to compare well with the test data, and is found to satisfactorily predict the frost thickness, frost surface temperature, frost density, and frost heat flux within the range of test conditions considered. It is revealed that the plate temperature has the greatest effect on frost thickness, and that both the plate temperature and relative humidity have considerably larger effect on frost thickness relative to the air velocity and air temperature. The model also exemplifies the experimental observation that the air velocity does not have appreciable effect on frost thickness, even though the frost density increases significantly as a result of increasing air velocity. The air temperature slightly increases the frost thickness, while it contributes to appreciable frost densification. The satisfactory comparisons of the model with test data over a wide range test of conditions suggests that the frost density and thermal conductivity models implemented in the proposed model seem to be well representative of the actual conditions.

\section{Acknowledgments}

The author would like to thank the reviewers for helpful suggestions in improving the manuscript. 


\section{References}

[1] B.W. Jones, J.D. Parker, Frost formation with varying environmental parameters, J. Heat Transfer 97 (1975) 255-259.

[2] B. Na, R.L. Webb, A new model for frost growth, Int. J. Heat Mass Transfer 47 (5) (2004) 925-936.

[3] D.L. O'Neal, D.R. Tree, A review of frost formation in simple geometries, ASHRAE Trans. 91 (1985) 267-281.

[4] J.D. Yonko, C.F. Sepsy, An investigation of the thermal conductivity of frost while forming on a flat horizontal plate, ASHRAE Trans. 73 (part 1) (1967), Paper No. 2043, $1.1-1.11$.

[5] R. Östin, R., S. Anderson, Frost growth parameters in a forced air stream, Int. J. of Heat Mass Transfer 34 (4/5) (1991) 1009-1017.

[6] K-S. Lee, W.S. Kim, T.H. Lee, A one-dimensional model for frost formation on a cold flat surface, Int. J. Heat and Mass Transfer 40 (18) (1997) 4359-4365.

[7] K-S. Lee, S. Jhee, D-K. Yang, Prediction of the frost formation on a cold flat surface, Int. J. Heat and Mass Transfer 46 (200 (2003) 3789-3796.

[8] C-H, Cheng, K-K. Wu, Observations of early-stage frost formation on a cold plate in atmospheric air flow, J. of Heat Transfer 125 (2003) 95-102.

[9] C.J.L. Hermes, R.O. Picucco, J.R. Barbosa, Jr., C. Melo, A study of frost growth and densification on flat surfaces, Experimental Thermal Fluid Sci. 33 (2009) 371-379.

[10] S.A. Sherif, S.P. Raju, M.M: Padki, A.B. Chen, A semi-empirical transient method for modeling frost formation on a flat plate, Int. J. of Refrigeration 16 (5) (1993) 321-329.

[11] P.L.T. Brian, R.C. Reid, I. Brazinsky, Cryogenic frost properties, Cryogenic Technology 5 (1969) 205-212.

[12] P.L.T. Brian, R.C. Reid, Y.T. Shah, Frost deposition on cold surfaces, I\&EC Fundamentals 9 (3) (1970) 375-380.

[13] S.M. Sami, T. Duong, Mass and heat transfer during frost growth, ASRAE Transactions 95 91) (1989) 158-165.

[14] Y.X. Tao, R.W. Besant, K.S. Rezkellah, A mathematical model for predicting the densification and growth of frost on a flat plate, Int. J. Heat and Mass transfer 36 (2) (1993) 353-363. 
[15] Sahin, A. G., An experimental study on the initiation and growth of frost formation on a horizontal plate, Experimental Heat Transfer 7 (1994) 85-95.

[16] R. Le Gall, J.M. Grillot, C. Jallut, Modeling of frost growth and densification, Int. J. of Heat Mass Transfer 40 (130 (1997) 3177-3187.

[17] C-H. Cheng, Y-C. Cheng, Predictions of frost growth on a cold plate in atmospheric air, Int. J. Heat Mass Transfer 28 (7) (2001) 953-962.

[18] Y.T. Shah, Theory of frost formation, Ph. D. Thesis, Massachusetts Institute of Technology, 1969.

[19] W. Woodside, Calculation of the thermal conductivity of porous media, Canadian J. of Phys. 36 (7) (1958) 815-823.

[20] M.A. Dietenberger, Generalized correlation of the water frost thermal conductivity, Int. J. Heat Mass Transfer 26 (4) (1983) 607-619.

[21] J. Shin, A.V. Tikhonov, C. Kim, Experimental study on frost structure on surfaces with different hydrophilicity: Density and thermal conductivity, J. Heat transfer 125 (2003) 84-94.

[22] D-K. Yang, K-S. Lee, Dimensionless correlation of frost properties on a cold plate, Int. J. Refrigeration 27 (1) (2004) 89-96.

[23] M. Kandula, Correlation of water frost thermal conductivity in laminar flow over flat surfaces. submitted to Special Topics and Reviews in Porous Media, July 2010.

[24] Y. Hayashi, A. Aoki, S. Adachi, K. Hori, Study of frost properties correlating with frost formation types, J. of Heat Transfer 99 (1997) 239-245.

[25] M. Kandula, On the effective thermal conductivity of frost considering mass diffusion and eddy convection, Special Topics and Reviews in Porous Media 1 (4) (2010) 321 336.

[26] P. Zehner, E.U. Schlunder, Thermal conductivity of granular materials at moderate temperatures (in German), Chemie Ingr. Tech. 42 (1970) 933-941.

[27] Hsu, C.T., P. Cheng, K.W. Wong, Modified Zehner-Schlunder models for stagnant thermal conductivity of porous media, Int. J. of Heat Mass Transfer 37 (17) (1994) 2751-2759.

[28] P. Cheng, C-T. Hsu, The effective stagnant thermal conductivity of porous media with periodic structures, J. of Porous Media 2 (1) (1999) 19-38. 
[29] M. Kandula, On the effective thermal conductivity of porous packed beds with uniform spherical particles, accepted for publication in J. of Porous Media, February 2010.

[30] G. Biguria, L.A. Wenzel, Measurement and correlation of water frost conductivity and density, I\&EC Fundamentals 9 (1) (1970) 129-138.

[31] P. Cheng, D. Vortmeyer, Transverse thermal dispersion and wall channeling in a packed bed with forced convective flow, Chem. Engng. Sci. 9 (1988) 2523-2532.

[32] C.T., Hsu, P. Cheng, Thermal dispersion in a porous medium, Int. J. of Heat and Mass Transfer 33 (8) (1990) 1587-1597, 1990.

[33] K. Vafai, Convective flow and heat transfer in variable-porosity media, J. Fluid Mechanics 147 (1984) 233-259.

[34] M. Sturm, J. Holmgen, M. Konig, K. Morris, The thermal conductivity of seasonal snow, J. Glaciology 43 (143) (1997) 26-41.

[35] M.S. Van Dusen, International Critical Tables 5, McGraw-Hill Book Co., 1929, p. 216.

[36] D. Pitman, B. Zuckerman, Effective thermal conductivity of snow at $-88^{\circ},-27^{\circ}$, and $5^{0} \mathrm{C}$, J. of Applied Phys. 38 (1967) 2698-2699.

[37] W.M. Kays, M.E. Crawford, Convective Heat and Mass Transfer, second ed., McGrawHill, New York, 1980.

[38] E.R.G. Eckert, R.M. Drake, Analysis of Heat and Mass Transfer, McGraw-Hill, New York, 1972.

[39] H.R. Pruppacher, J.D. Klett, Microphysics of Clouds and Precipitation, Reidel, Dordrecht, 1978.

[40] P.G. Mago, S.A. Sherif, Frost formation and heat transfer on a cold surface in ice fog, AIAA-2004-164, 2004.

[41] P.J. Flatau, R.L. Walka, R. L., W.R. Cotton, Polynomial fits to saturation vapor pressure, J. of Meteorology 31 (1992) 1507-1513.

[42] W.M. Rohsenow, J.P. Hartnett, Handbook of Heat Transfer, McGraw-Hill, New York, 1973.

[43] D.S. Dillard, K.D. Timmerhaus, Low temperature thermal conductivity of selected dielectric crystalline solids, in Thermal Conductivity, in: C.T. Ho and R.E. Taylor (Ed.), Proceedings of the 8th Conference, Plenum Press, New York, 1969, pp. 949-967. 
[44] S. Ellgas, M. Pfitzner, Modeling frost formation within a commercial CFD code, Numerical Heat Transfer, Part A 53 (2008) 485-506. 


\section{Figure Captions}

Fig. 1. Schematic of porous frost growth.

Fig. 2. Correlation for the frost porosity and frost density as a function of dimensionless frost surface temperature and flow Reynolds number (adapted from Kandula [23]).

Fig. 3. Comparisons of predicted thermal conductivity of frost with the correlations of Sturm et al. [34], Van Deusen [35], and Östin and Anderson [5].

Fig. 4. Comparison of the present model with the data of Yonko and Sepsy [4] for frost thickness indicating the role of relative humidity, wall temperature and air velocity. data for (a): Run \# 13: $T_{\infty}=295 \mathrm{~K}, \omega_{\infty}=0.0108, u_{\infty}=2.96 \mathrm{~m} / \mathrm{s}$; Run \# 14: $T_{\infty}=295 \mathrm{~K}, \omega_{\infty}=$ $0.0106, u_{\infty}=2.57 \mathrm{~m} / \mathrm{s}$; Run \# 15: $T_{\infty}=296 \mathrm{~K}, \omega_{\infty}=0.0117, u_{\infty}=2.92 \mathrm{~m} / \mathrm{s}$; data for (b): Run \#7: $T_{\infty}=294 \mathrm{~K}, T_{w}=245 \mathrm{~K}, u_{\infty}=1.26 \mathrm{~m} / \mathrm{s}$; Run \#10: $T_{\infty}=296 \mathrm{~K}, T_{w}=245 \mathrm{~K}, u_{\infty}=1.37$ $\mathrm{m} / \mathrm{s}$; data for (c): Run \#9: $T_{\infty}=294 \mathrm{~K}, T_{w}=245 \mathrm{~K}, \omega_{\infty}=0.009$.

Fig. 5. Comparison of the present model with the data of Cheng and $\mathrm{Wu}$ [8] for frost thickness showing the effects of air velocity, air temperature; and relative humidity; (a) and (c) are adapted from Cheng and Wu [8]; data for (a) and (b): $T_{\infty}=300.8 \mathrm{~K}, T_{w}=262.8$ $\mathrm{K}$, and $\phi_{\infty}=42 \%$; data for (c) and (d): $T_{w}=261.9 \mathrm{~K}, \phi_{\infty}=76 \%$, and $u_{\infty}=2.3 \mathrm{~m} / \mathrm{s}$; data for (e) and (f): Set \#11, $T_{\infty}=300.1 \mathrm{~K}, T_{w}=266 \mathrm{~K}, \phi_{\infty}=41 \%$, and $u_{\infty}=4.2 \mathrm{~m} / \mathrm{s}$; Set $\# 12, T_{\infty}=$ $299.7 \mathrm{~K}, T_{w}=268 \mathrm{~K}, \phi_{\infty}=72 \%$, and $u_{\infty}=6.1 \mathrm{~m} / \mathrm{s}$.

Fig. 6. Comparison of the present model with the data of Lee et al. [6] for frost thickness and frost surface temperature at varying relative humidity and air velocity. Fig. 7. Comparison of the present model with the data of Lee et al. [7] for frost thickness, frost surface temperature, frost density, and frost heat flux; data: $T_{\infty}=288.2$ $\mathrm{K}, T_{w}=258.2 \mathrm{~K}, \omega_{\infty}=0.00633 \mathrm{~kg}_{\mathrm{v}} / \mathrm{kg}_{\mathrm{a}}$, and $u_{\infty}=2.5 \mathrm{~m} / \mathrm{s}$.

Fig. 8. Comparison of the present model with the data of Hermes et al. [9] for frost thickness at four different wall temperatures.

\section{Table Captions}

Table 1. Comparison of predictions with the test data of Hermes et al. [9] for frost parameters (test conditions: $T_{\infty}=289.2 \mathrm{~K}, u_{\infty}=0.7 \mathrm{~m} / \mathrm{s}$ ). 
Table 1. Comparison of predictions with the test data of Hermes et al. [9] for frost parameters (test conditions: $T_{\infty}=289.2 \mathrm{~K}, u_{c o}=0.7 \mathrm{~m} / \mathrm{s}$ ).

\begin{tabular}{|c|c|c|c|c|c|c|c|c|c|}
\hline \multirow[t]{2}{*}{ Run \# } & \multirow[t]{2}{*}{$\phi_{\infty}(0)$} & \multirow{2}{*}{$\begin{array}{c}T_{w} \\
\left({ }^{0} \mathrm{C}\right)\end{array}$} & \multirow[t]{2}{*}{$t(\min )$} & \multicolumn{2}{|c|}{$x_{s}(\mathrm{~mm})$} & \multicolumn{2}{|c|}{$T_{f s}\left({ }^{0} \mathrm{C}\right)$} & \multicolumn{2}{|c|}{$\rho_{f}\left(\mathrm{~kg} / \mathrm{m}^{3}\right)$} \\
\hline & & & & data & predicted & data & predicted & data & predicted \\
\hline D-7 & 80 & -15 & 60 & 2.91 & 2.28 & -6.3 & -7.9 & 85.3 & 89.8 \\
\hline " & $"$ & $"$ & 120 & 3.84 & 3.22 & -5.6 & -6.7 & 127.0 & 116.2 \\
\hline D-8 & $"$ & -10 & 60 & 2.25 & 1.95 & -5.2 & -5.1 & 104.6 & 97.1 \\
\hline$"$ & $"$ & $"$ & 120 & 2.99 & 2.76 & -3 & -4.2 & 153.3 & 126.2 \\
\hline $\mathrm{D}-9$ & ", & -5 & 60 & 1.7 & 1.45 & -2.4 & -2.3 & 136.6 & 116.6 \\
\hline$"$ & $"$ & $"$ & 120 & 2.28 & 2.04 & -1.4 & -1.8 & 191.6 & 152.3 \\
\hline D-10 & 50 & -15 & 60 & 1.88 & 1.83 & -7.6 & -9.3 & 82.0 & 65.0 \\
\hline$"$ & $"$ & ", & 120 & 2.65 & 2.56 & -6.4 & -8.2 & 107.8 & 85.0 \\
\hline D-11 & ", & -10 & 60 & 1.57 & 1.55 & -5.3 & -6.1 & 84.7 & 67.4 \\
\hline$"$ & ", & $"$ & 120 & 2.21 & 2.15 & -4.0 & -5.3 & 116.5 & 88.5 \\
\hline D-12 & ", & -5 & 60 & 0.99 & 1.10 & -3.4 & -2.9 & 112.5 & 75.8 \\
\hline " & ", & ", & 120 & 1.52 & 1.52 & -2.6 & -2.5 & 137.1 & 99.8 \\
\hline
\end{tabular}


mass transfier of vapor to the firosl surlace



(a)

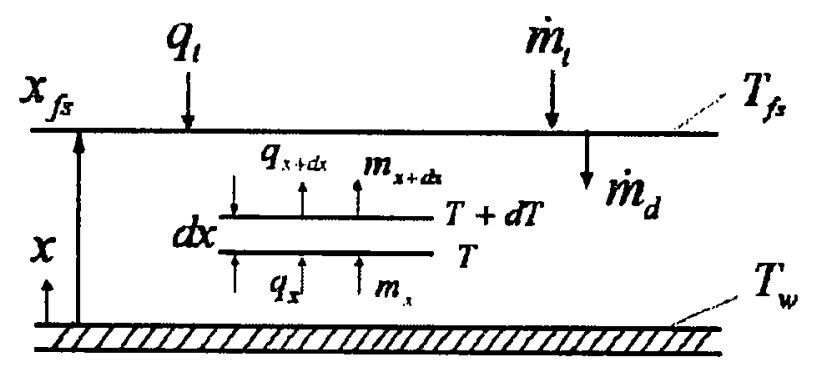

(b)

Fig. 1. Schematic of porous frost growth. 


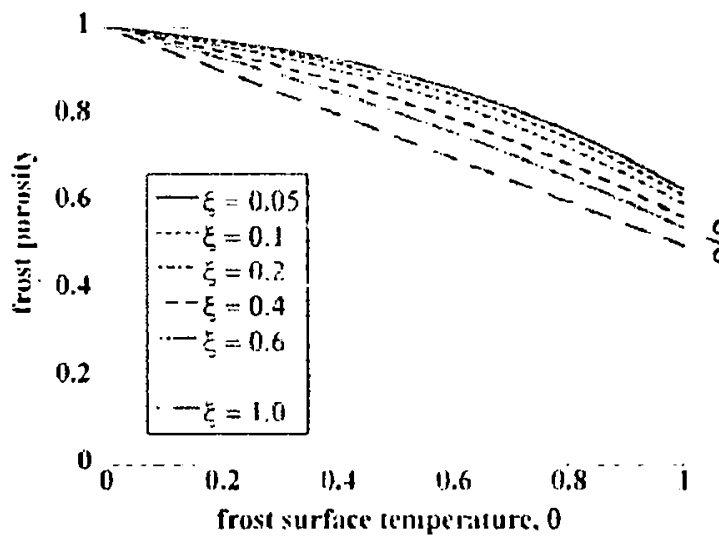

(a)

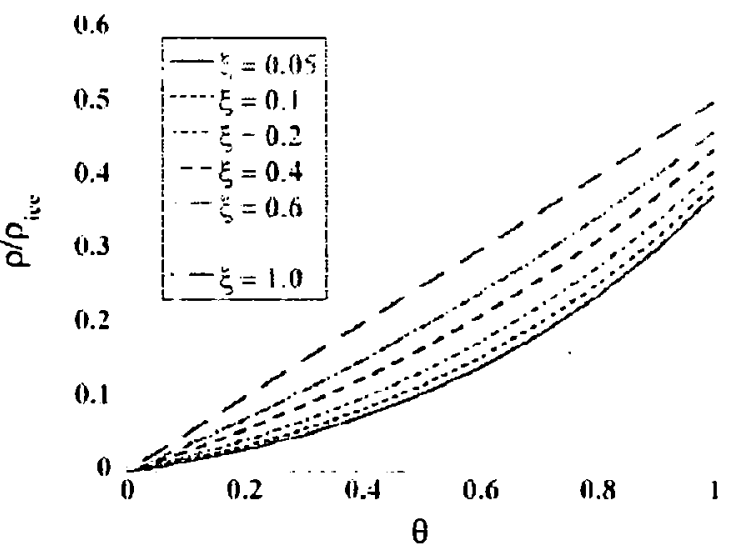

(b)

Fig. 2. Correlation for the frost porosity and frost density as a function of dimensionless frost surface temperature and flow Reynolds number (adapted from Kandula [23]). 


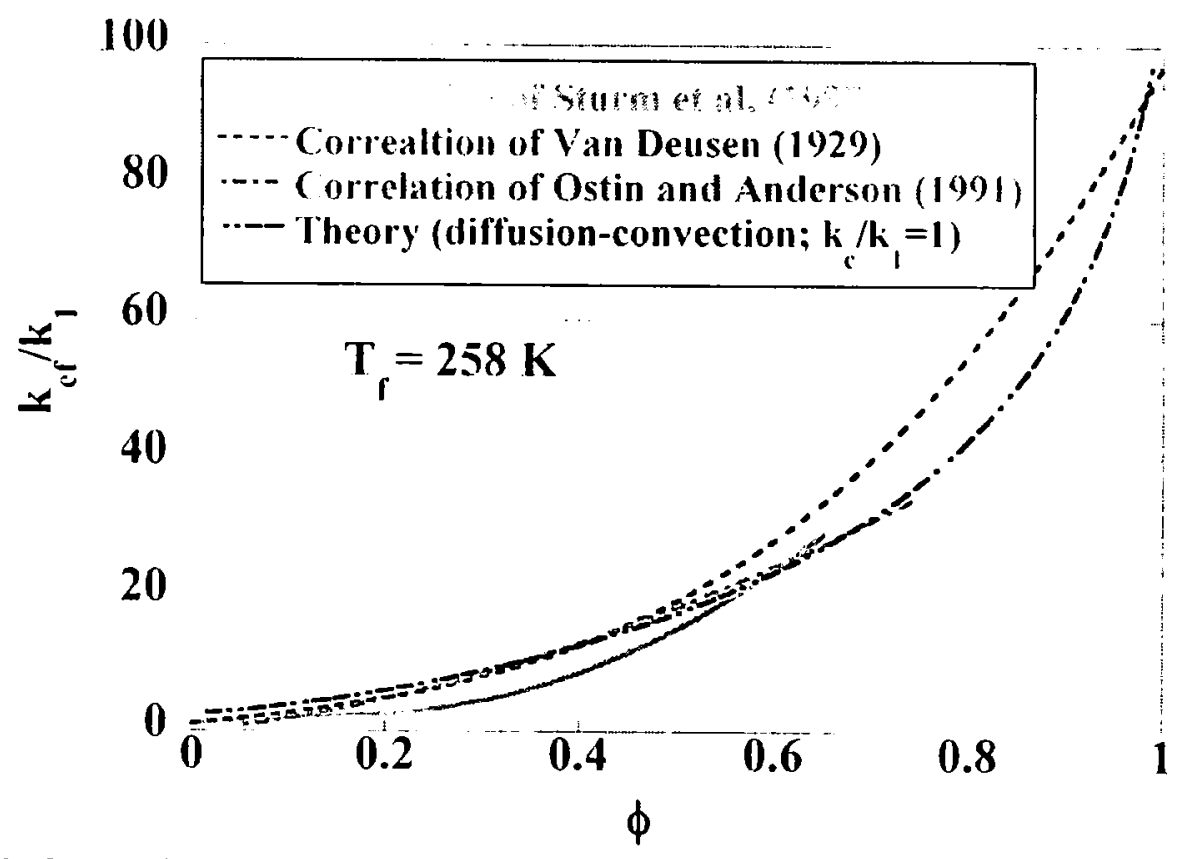

Fig. 3. Comparisons of predicted thermal conductivity of frost with the correlations of Sturm et al. [34], Van Deusen [35], and Östin and Anderson [5]; adapted from Kandula [25]). 




(a)

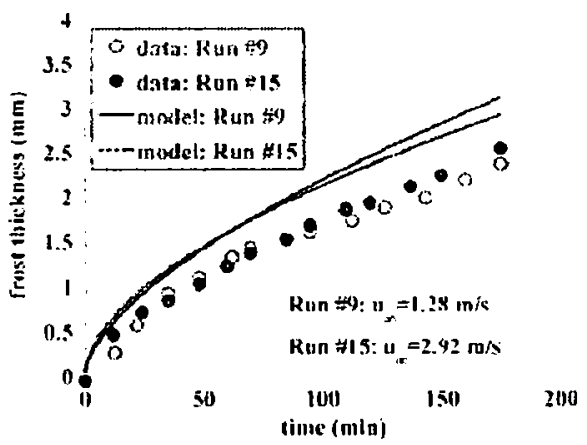

(c)

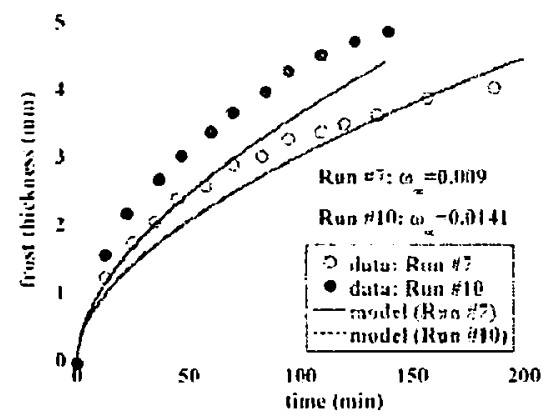

(b)

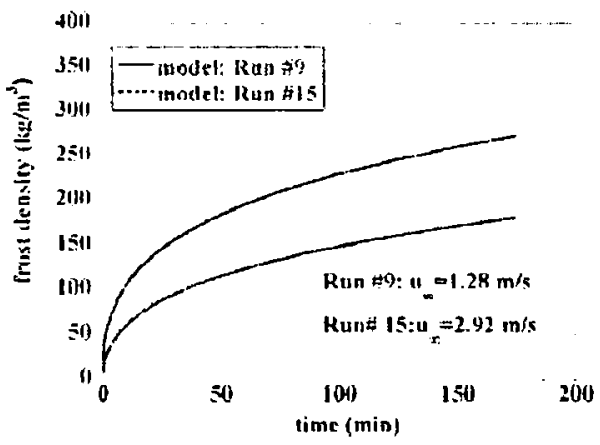

(d)

Fig. 4. Comparison of the present model with the data of Yonko and Sepsy [4] for frost thickness indicating the role of relative humidity, wall temperature and air velocity. data for (a): Run \# 13: $T_{\infty}=295 \mathrm{~K}, \omega_{\infty}=0.0108, u_{\infty}=2.96 \mathrm{~m} / \mathrm{s}$; Run \# 14: $T_{\infty}=295 \mathrm{~K}, \omega_{\infty}=$ $0.0106, u_{\infty}=2.57 \mathrm{~m} / \mathrm{s}$; Run \# 15: $T_{\infty}=296 \mathrm{~K}, \omega_{\infty}=0.0117, u_{\infty}=2.92 \mathrm{~m} / \mathrm{s}$; data for (b): Run $\# 7: T_{\infty}=294 \mathrm{~K}, T_{w}=245 \mathrm{~K}, u_{\infty}=1.26 \mathrm{~m} / \mathrm{s}$; Run \#10: $T_{\infty}=296 \mathrm{~K}, T_{w}=245 \mathrm{~K}, u_{\infty}=1.37$ $\mathrm{m} / \mathrm{s}$; data for (c): Run \#9: $T_{\infty}=294 \mathrm{~K}, T_{w}=245 \mathrm{~K}, \omega_{\infty}=0.0110$. 


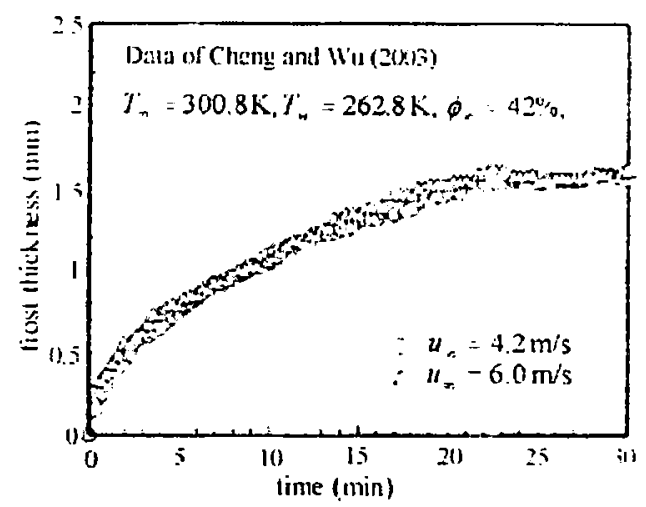

(a)

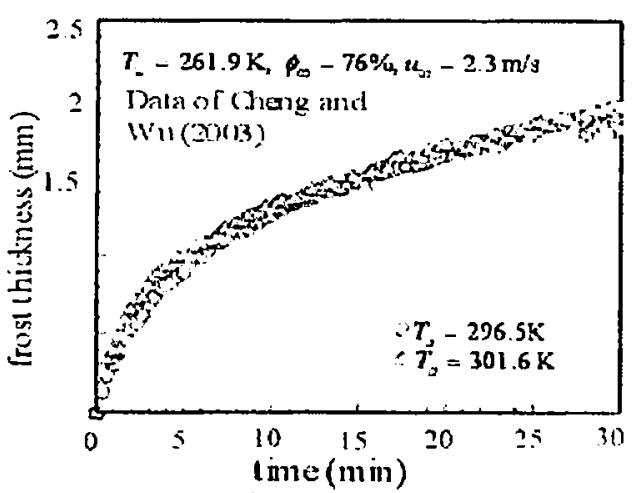

(c)

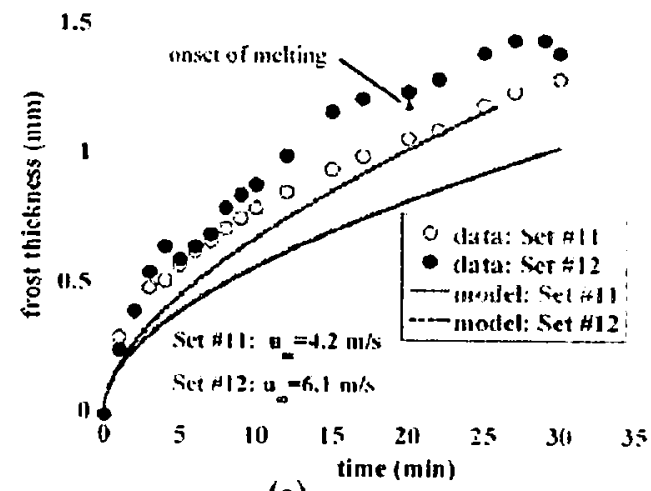

(e)

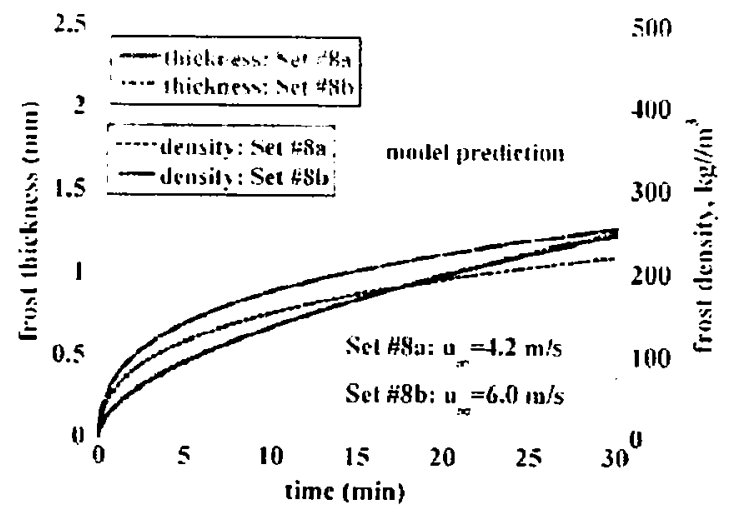

(b)



(d)

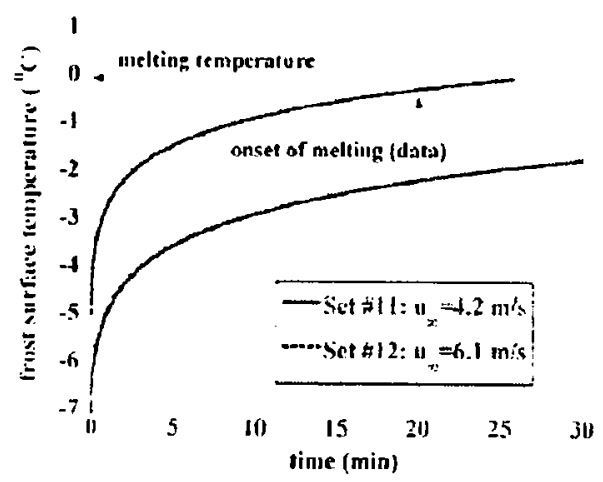

(f)

Fig. 5. Comparison of the present model with the data of Cheng and $\mathrm{Wu}$ [8] for frost thickness showing the effects of air velocity, air temperature; and relative humidity; (a) and (c) are adapted from Cheng and Wu [8]; data for (a) and (b): $T_{\infty}=300.8 \mathrm{~K}, T_{w}=262.8$ $\mathrm{K}$, and $\phi_{\infty}=42 \%$; data for (c) and (d): $T_{w}=261.9 \mathrm{~K}, \phi_{\infty}=76 \%$, and $u_{\infty}=2.3 \mathrm{~m} / \mathrm{s}$; data for (e) and (f): Set \#11, $T_{\infty}=300.1 \mathrm{~K}, T_{w}=266.0 \mathrm{~K}, \phi_{\infty}=41 \%$, and $u_{\infty}=4.2 \mathrm{~m} / \mathrm{s}$; Set \#12, $T_{\infty}=299.7 \mathrm{~K}, T_{w}=268.2 \mathrm{~K}, \phi_{\infty}=72 \%$, and $u_{\infty}=6.1 \mathrm{~m} / \mathrm{s}$. 


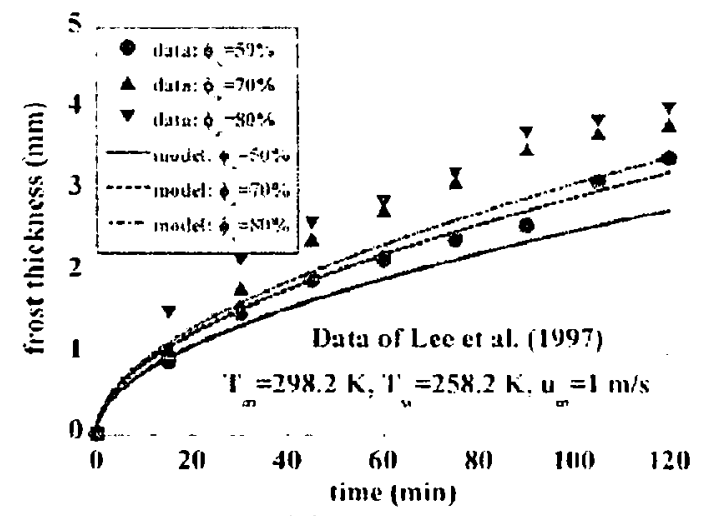

(a)

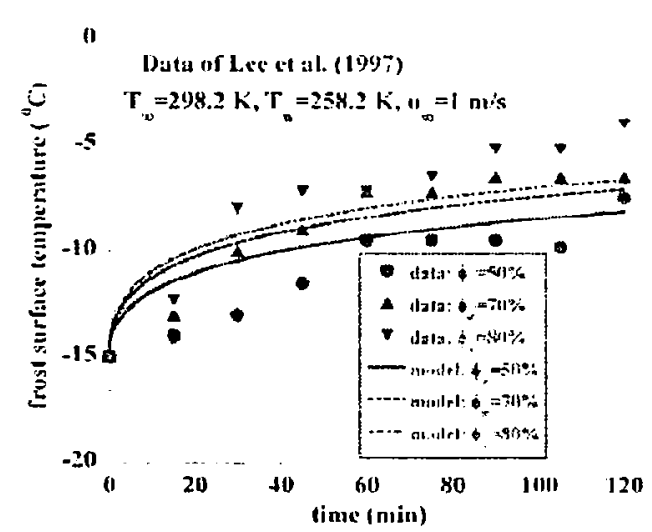

(b)



(c)

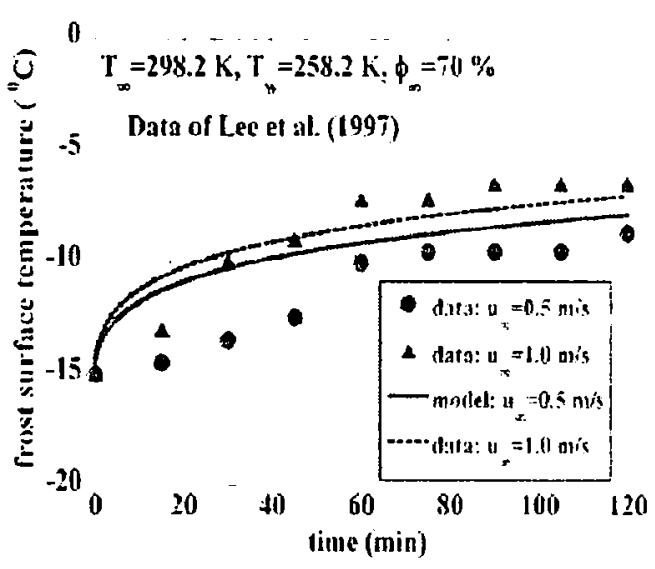

(d)

Fig. 6. Comparison of the present model with the data of Lee et al. [6] for frost thickness and frost surface temperature at varying relative humidity and air velocity. 


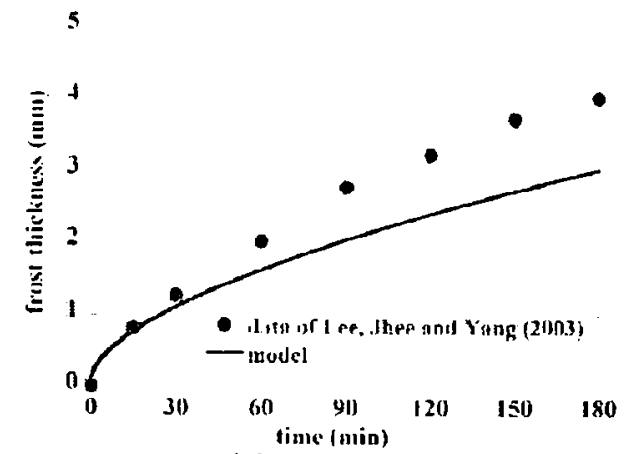

(a)



(c)



(b)

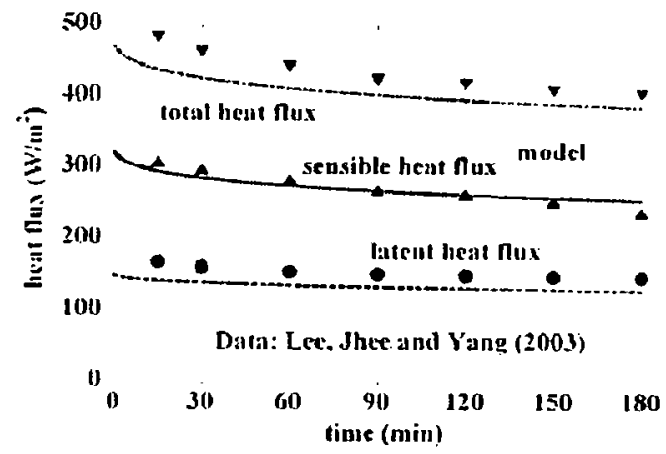

(d)

Fig. 7. Comparison of the present model with the data of Lee et al. [7] for

frost thickness, frost surface temperature, frost density, and frost heat flux; data: $T_{\infty}=288.2$ $\mathrm{K}, T_{w}=258.2 \mathrm{~K}, \omega_{\infty}=0.00633 \mathrm{~kg}_{\mathrm{v}} / \mathrm{kg}_{\mathrm{a}}$, and $u_{\infty}=2.5 \mathrm{~m} / \mathrm{s}$. 




Fig. 8. Comparison of the present model with the data of Hermes et al. [9] for frost thickness at four different wall temperatures. 